\title{
Utility of Nasogastric Tube for Medical and Surgical Oncology of Gastric Cancer: A Prospective Institutional Study on a New and Precious Application of an Old and Economic Device
}

\author{
EDOARDO VIRGILIO ${ }^{1}$, GENOVEFFA BALDUCCI ${ }^{1}$, PAOLO MERCANTINI $^{1}$, \\ ENRICO GIARNIERI ${ }^{2}$, MARIA ROSARIA GIOVAGNOLI ${ }^{2}$, MONICA MONTAGNINI $^{2}$, \\ ANTONELLA PROIETTI ${ }^{2}$, ROSARIA D'URSO ${ }^{2}$ and MARCO CAVALLINI ${ }^{1}$ \\ ${ }^{1}$ Medical and Surgical Sciences and Translational Medicine, \\ Faculty of Medicine and Psychology "Sapienza", St. Andrea Hospital, Rome, Italy; \\ ${ }^{2}$ Department of Clinical and Molecular Medicine, Faculty of Medicine and Psychology, \\ University "Sapienza”, St. Andrea Hospital, Rome, Italy
}

\begin{abstract}
Background/Aim: Concerning gastric cancer $(G C)$, nasogastric tube (NGT) is routinely employed for perioperative decompression and palliative enteral nutrition. Additionally, we believe to have found a further application. Patients and Methods: Between April 2012 and April 2017, 96 GC patients received preoperative nasogastric lavage $(G L)$. All samples were cytologically examined to detect the presence (GL1) or absence (GLO) of malignant cells. Data were analyzed with classificatory, staging and prognostic purpose. Results: GL1 was detected in 46 GC patients: association with tumor depth, lymph node and distant metastasis, lymphovascular and peri-neural invasion, diffuse type and signet-ring cells was significant (respectively $p=0.0274,0.0324,0.0446,0.0287,<0.0001,0.0413$, $<0.0001)$. GL1 entailed significantly poorer overall (OS), progression-free, disease-free survival and tumor progression (18 vs. 32 months). At multivariate analysis, GL1 was an independent prognostic factor for worse OS ( $p=0.0287)$. Conclusion: NGT seems an economic oncologic measure useful for obtaining information on GC staging and prognosis.
\end{abstract}

Presently, nasogastric tube (NGT) insertion is one of the simplest clinical procedures most frequently performed throughout the world: common indications include

Correspondence to: Prof. Edoardo Virgilio, Medical and Surgical Sciences and Translational Medicine, Faculty of Medicine and Psychology "Sapienza", St. Andrea Hospital, via di Grottarossa 103539, 00189, Rome, Italy. Tel: +39 0633775693, Fax: +39 0633775322, e-mail: aresedo1992@yahoo.it, edoardo.virgilio@uniroma1.it

Key Words: Nasogastric tube, gastric cancer, gastric lavage, gastric cancer oncology, gastric cancer cytopathology. gastrointestinal disorders, surgery and trauma events (1). Historically, the first descriptions date back to 1598 and 1617 when two Italian anatomists, Gerolamo Capivaccio ab Padova and Gerolamo Fabrizio ab Aquapendente, respectively resorted to a rudimental nasogastric pipe with feeding and cleansing purpose (2). In 1812, Physick performed the first gastric lavage (GL) through NGT with decontamination intent; today, although often controversial, antitoxic GL still remains the measure of choice when no antidote exists or usual therapies are ineffective (3). In 1867, Adolf Kussmaul pioneered GL with decompression intent while in 1921 Abraham Louis Levin introduced the Levin NGT after gastrointestinal surgery and for management of trauma patients. In 1959, Wangensteen and colleagues successfully resorted to iced GL through NGT to stop hemorrhage from the upper gastrointestinal tract; today, though matter of controversies, this is still one of the most fascinating and useful applications of NGT (4). More recently, nasogastric washing has been associated with prompt diagnosis of pulmonary tuberculosis in children who cannot produce sputum and prevention of feeding problems in neonates with meconium-stained amniotic fluid $(5,6)$.

In the setting of gastric cancer (GC), as of 2017, NGT placement has been traditionally adopted to provide perioperative decompression of the stomach, permit enteral nutrition as palliative care and reduce postoperative bleeding after endoscopic submucosal dissection (ESD) of early GC (EGC) (7-9). Collection of GL from GC patients represents another historical application of this device (10-12). In the pre-endoscopy era, in fact, cytologic examination of GL was commonly used to obtain preoperative diagnosis of GC (1012). Since 1970s, however, following the overwhelming results achieved by gastroscopic biopsy in terms of diagnostic sensitivity and specificity, GC cytology has been 


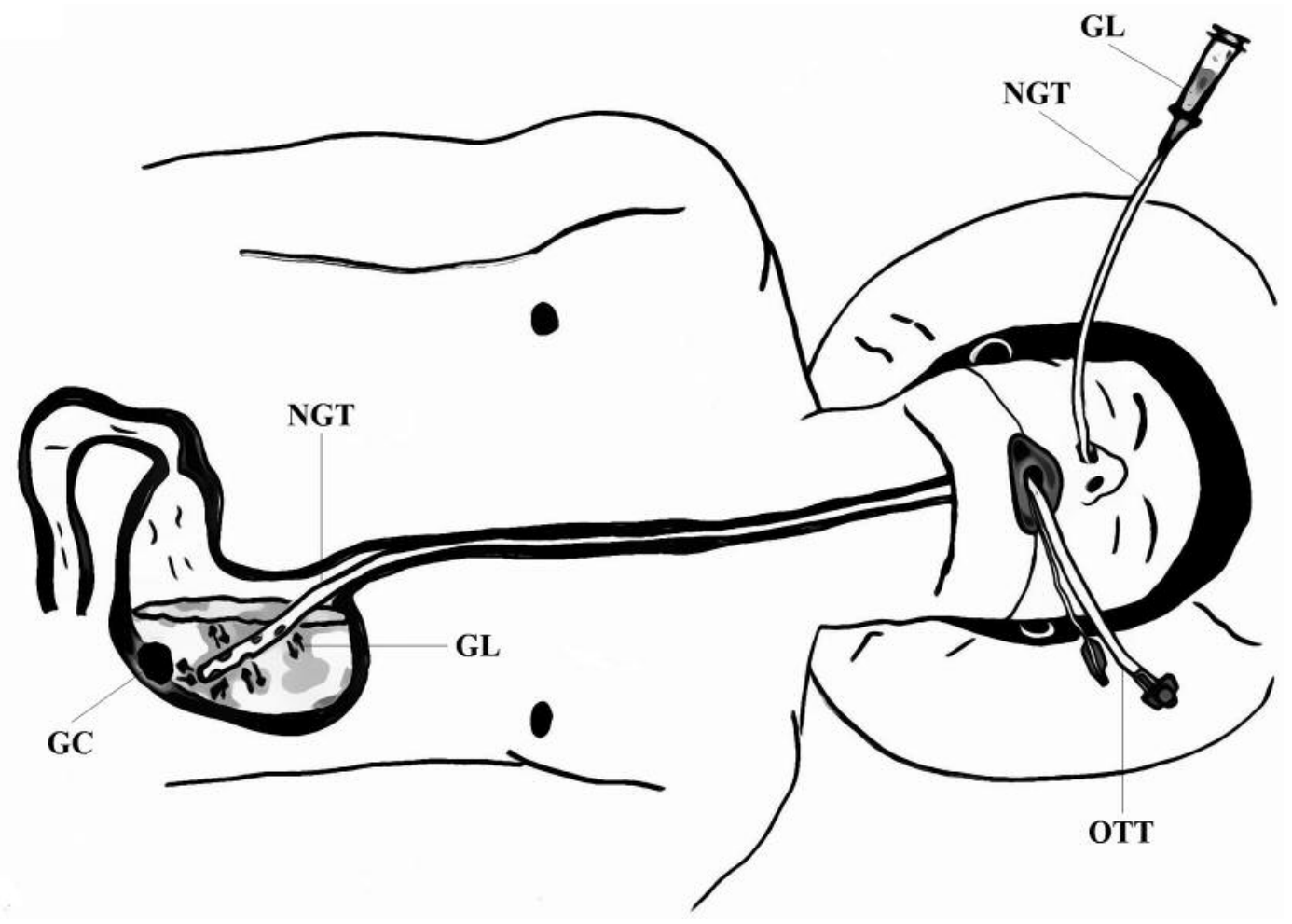

Figure 1. Illustration of the gastric lavage (GL) procedure from a top left side view. A total amount of 500 milliliters of sterile saline solution is injected and aspirated through nasogastric tube (NGT) using a $60 \mathrm{ml}$ plastic syringe with conical tip. Washing the entire gastric lumen back and forth several times (upward and downward arrows) is supposed to bath the gastric cancer (GC) and collect the exfoliated malignant cells. OTT: Orotracheal tube.

progressively abandoned $(13,14)$. In this study, our aim was to shed novel light to GC cytopathology investigating the presence or the absence of malignant cells exfoliated in GL of GC patients not only with a descriptive-diagnostic intent, but mostly for staging and prognostic purpose. As discussed in more detail below, we think this kind of cytologic analysis an innovative perspective to improve the current knowledge on GC and reckon NGT as the indispensable device for reaching that.

\section{Materials and Methods}

Nasogastric intubation. Between April 2012 and April 2017, 96 patients affected with GC (gastric adenocarcinoma) and amenable to surgical treatment have been prospectively enrolled in this observational study in accordance with the ethical standards laid down in the Declaration of Helsinki (as revised in Brazil 2013). Informed consent was obtained before participation; initial results have already been disclosed in former researches on GC (15-17). All subjects required NGT (Levin type, Ch 14 to 18, Bıçakçılar Tıbbi Cihazlar San. ve Tic. A.Ş., Istanbul, Turkey) during hospital stay at the Division of General and Emergency Surgery of St. Andrea Hospital, Faculty of Medicine and Psychology, University of Sapienza, Rome, Italy. In the operating room, after orotracheal intubation but prior to surgical incision, each hollow viscus was irrigated through NGT with 500 milliliters of saline solution under sterile conditions (12); a minimum quantity of $250 \mathrm{ml}$ was estimated sufficient in the case of obstructing cardial carcinomas and gastric stump cancers (Figure 1). The retrieved gastric lavage (GL) was immediately transferred to the Cytology Department of our hospital to detect the presence or absence of cancer cells. The following morphological criteria were considered congruent with the preoperative histological diagnosis of GC: pleomorphism, hypertrophy, nuclear changes, increased and/or abnormal mitotic figures, high nucleus-to-cytoplasm ratio, nucleolar hypertrophy, highly condensed nuclear chromatin and the presence of signet-ring cells, aggregates or pseudopapillary clusters. Last, cytological findings were compared to the traditional clinicopathologic parameters of GC and further analyzed to test their prognostic value. Histology of surgical specimens was described following the 7 th AJCC TNM Staging System (18).

Statistical analysis. Statistical analysis was performed using MedCalc Statistical Software for Windows, version 17.5.5 (MedCalc Software bvba, Ostend, Belgium). Discrete variables were compared using the Pearson's Chi-square test, whereas continuous data were presented as mean and analyzed through the Student's $t$-test. Four types of survival were investigated: median overall survival rate 
(OS), defined as the time from GL collection to death from any cause, progression-free survival (PFS) defined as the time elapsed between GL retrieval and tumor progression or death from any cause, disease-free survival (DFS), described as the span of life between GL and any local recurrence, distant metastasis or death from any cause and time to tumor progression (TTP) representing the length of time from GL to tumor progression or cancer-related death. All the survival curves were plotted using the Kaplan-Meier method and compared with the log rank test. Univariate analysis was performed using two-way ANOVA test while Cox proportional hazards model was used in multivariate analysis to assess independent prognostic factors. $p$-Values $\leq 0.05$ were considered statistically significant.

\section{Results}

Clinicopathologic features. The main clinicopathologic features of the examined population have been summarily discussed previously (16) and are summarized in Table I. Altogether, 93 patients (97\%) were submitted to surgery; after initial evaluation, 2 patients with advanced GC were scheduled to palliative enteral feeding while one EGC woman to ESD. Among the surgical candidates, open surgery with curative intent was accomplished in 79 patients (35 total gastrectomies, 40 distal gastrectomies with Roux-en-Y reconstruction and 4 Billroth 2 partial gastrectomies); at laparotomy, 14 more patients were found with inoperable GC and were managed by palliative gastroenterostomy ( 2 cases), nutritional Witzel jejunostomy (8 cases) or sent to palliative chemotherapy (4 cases). At conclusive histology of resected specimens, surgical margins resulted infiltrated in 9 cases $(11.4 \%)$. Twenty-one patients received neoadjuvant treatment: of these, chemotherapy alone was administered in 17 (EOX, ECF and DCF were the regimens more frequently adopted) and combined radio-chemotherapy in 4 cases. A total of 45 patients were given adjuvant treatment: radiochemotherapy was employed in 26 , chemotherapy alone in 17 and irradiation alone in 3 cases.

GL cytologic evaluation. Cytologic examination of GL demonstrated the presence (GL1) and absence (GL0) of cancer cells respectively in $46(47.9 \%)$ and $50(52.1 \%) \mathrm{GC}$ patients: of note, GL1 correlated with statistical significanceto the parameters of tumor depth (T3-T4 vs. T1$\mathrm{T} 2)$, lymph node metastasis $(\mathrm{N}+v s . \mathrm{N} 0)$, distant metastasis (M1 vs. M0), lymphovascular invasion (LVI1 vs. LVI0), perineural invasion (PnI1 vs. PnI0), Lauren classification (diffuse $v s$. intestinal histology), presence of signet-ring cells and administration of palliative treatment (respectively $p=0.0274, p=0.0324, p=0.0446, p=0.0287, p<0.0001$, $p=0.0413, p<0.0001, p=0.0184)$ (Table II).

Survival. After a median follow-up of 33.8 months (range=262 months) 55 patients had deceased: cancer-related deaths were 49 whereas fatal perioperative complications occurred
Table I. Main clinicopathologic features of the 96 GC patients.

\begin{tabular}{|c|c|}
\hline Gender & $\begin{array}{l}\text { M: } 54(56.2 \%) \\
\text { F: } 42(43.7 \%)\end{array}$ \\
\hline Age (mean) & 66 years (range: 39 to 90 ) \\
\hline Tumor site & $\begin{array}{c}\text { Distal*: } 48(50 \%) \\
\text { Proximal*: } 48(50 \%)\end{array}$ \\
\hline $\mathrm{T}$ & $\begin{array}{l}\text { T1a: } 7 \text { cases }(7.3 \%) \\
\text { T1b: } 9 \text { cases }(9.3 \%) \\
\text { T2: } 13 \text { cases }(13.5 \%) \\
\text { T3: } 24 \text { cases }(25 \%) \\
\text { T4a: } 20 \text { cases }(21 \%) \\
\text { T4b: } 23 \text { cases }(24 \%)\end{array}$ \\
\hline $\mathrm{N}$ & $\begin{array}{c}\text { N0: } 26 \text { cases }(27 \%) \\
\text { N1: } 16 \text { cases }(16.5 \%) \\
\text { N2: } 15 \text { cases }(15.5 \%) \\
\text { N3a: } 15 \text { cases }(15.5 \%) \\
\text { N3b: } 26 \text { cases }(27 \%)\end{array}$ \\
\hline M & $\begin{array}{l}\text { M0: } 73 \text { cases }(76 \%) \\
\text { M1: } 23 \text { cases }(24 \%)\end{array}$ \\
\hline Stage & $\begin{array}{l}\text { 1A: } 16 \text { cases }(16.5 \%) \\
\text { 1B: } 6 \text { cases }(6.25 \%) \\
\text { 2A: } 3 \text { cases }(3 \%) \\
\text { 2B: } 9 \text { cases }(9 \%) \\
\text { 3A: } 10 \text { cases }(10.5 \%) \\
\text { 3B: } 20 \text { cases }(21 \%) \\
\text { 3C: } 8 \text { cases }(8 \%) \\
\text { 4: } 24 \text { cases }(25 \%)\end{array}$ \\
\hline G & $\begin{array}{c}\text { G1: } 12 \text { cases }(12.5 \%) \\
\text { G2: } 13 \text { cases }(13.5 \%) \\
\text { G3: } 57 \text { cases }(59 \%) \\
\text { G4: } 14 \text { cases }(14.5 \%)\end{array}$ \\
\hline Lauren classification & $\begin{array}{c}\text { Intestinal type: } 54 \text { cases }(56.25 \%) \\
\text { Diffuse type: } 28 \text { cases }(29 \%) \\
\text { Mixed-type: } 3 \text { cases }(3 \%) \\
\text { n.a.: } 11 \text { cases }(11.4 \%)\end{array}$ \\
\hline 2010 WHO classification & $\begin{array}{c}\text { Tubular: } 11 \text { cases }(11.4 \%) \\
\text { Mucinous: } 8 \text { cases }(8.3 \%) \\
\text { Poorly cohesive/signet-ring cells: } \\
31 \text { cases }(32.3 \%) \\
\text { Papillary: } 3 \text { cases }(3 \%) \\
\text { Solid sheets: } 3 \text { cases }(3 \%) \\
\text { n.a.: } 30 \text { cases }(31.25 \%)\end{array}$ \\
\hline LVI & $\begin{array}{l}\text { LVI0: } 39 \text { cases }(40.6 \%) \\
\text { LVI1: } 57 \text { cases }(59.4 \%)\end{array}$ \\
\hline PnI & $\begin{array}{l}\text { PnI0: } 64 \text { cases }(66.6 \%) \\
\text { PnI1: } 32 \text { cases }(33.4 \%)\end{array}$ \\
\hline LNR & $\begin{array}{c}0: 26 \text { cases }(27 \%) \\
1(>0-0.3): 28 \text { cases }(29 \%) \\
2(>0.3-0.6): 13 \text { cases }(13.5 \%) \\
3(>0.6): 29 \text { cases }(30 \%)\end{array}$ \\
\hline
\end{tabular}

*Distal site includes antro-pyloric cancers; proximal site includes cardial, corpo-fundic and gastric stump carcinomas. n.a.: Not assigned; LVI: lymphovascular invasion; PnI: peri-neural invasion; LNR: metastatic lymph node ratio.

to 6 patients. Of 31 male deaths, 17 were GL1 (54.85\%); of the 24 women that had deceased, 12 had GL1 (50\%). Altogether, $53 \%$ of deaths (29 subjects) had cancer cells in 
their GL (GL1). Concerning neoadjuvant subgroup, no statistical difference has come up between GL1 and GL0 patients in terms of survival. Of the 41patients alive in June 2017, one GL1 man developed recurrence at the anastomotic site and one more GL1 patient a metastatic liver disease. At Kaplan-Meier analysis, the median OS and PFS were of 18 and 32 months for GC patients respectively with positive and negative GL cytology $(p=0.017)$ (Figure $2 \mathrm{a}$ and $\mathrm{b})$. Of interest, GL1 GC patients, compared to GL0 ones, had also shorter DFS (17.6 vs. 31.5 months, $p=0.0134$ ) and TTP (19 $v s .35$ months, $p=0.0056$ ) (Figure $2 \mathrm{c}$ and $\mathrm{d}$ ). The univariate model revealed a strong correlation between GL and OS and PFS $(p=0.021)$, DFS $(p=0.020)$ and TTP $(p=0.024)$ (Table III). At multivariate analysis, GL1, Stage 3-4, M1, LVI1, PnI1, G3-G4 and necessity of adjuvant treatment resulted to be independent prognostic factors for poor OS (respectively $p=0.0287, p=0.0277, p=0.0161, p=0.0471, p=0.0299$, $p=0.0226$ and $p=0.0048$ ) (Table IV). LVI1 was also the only multivariate independent factor for DFS $(p=0.0144)$ whereas no variable reached significance for PFS and TTP.

\section{Discussion}

Our study aimed at renewing interest in the use of cytology for GC patients. Prior to the advent of flexible gastroscopy at around 1970s, several cytologic works have formerly examined GL of GC patients but only from a diagnostic point of view (10-12). As a consequence, when the gastroscopic biopsy demonstrated superior sensitivity and specificity for GC diagnosis, cytopathology was abandoned $(13,14)$. This time, diverging from previously published literature, we resorted to this type of analysis not only with descriptive intent, but mainly for classificatory, staging and prognostic purpose. In fact, after retrieval of the biological material, we did not confine the research only to detecting the presence (GL1) or the absence (GL0) of malignant cells exfoliated in it, but we also investigated the correlation between the cytologic data and the other clinicopathologic features already recognized for GC. Similarly to our previous results from $38 \mathrm{GLs}$, the correlation herein presented has identified GL1 as a parameter of aggressive tumor phenotype (15). In fact, GL1 has shown a statistically significant association with other well-known indicators of aggressive tumor behavior such as advanced tumor depth (T3-T4), N+, M1, LVI1, PnI1, Lauren's diffuse type, presence of signet-ring cells and administration of palliative treatment (respectively, $p=0.0274,0.0324,0.0446,0.0287$, $<0.0001,0.0413,<0.0001$ and 0.0184) (Table II). We observed an interesting and relevant clinical correspondence between these statistics and survival data: compared to GL0 group with the Kaplan-Meier method, in fact, GL1 patients met with significantly poorer OS and PFS (18 vs. 32 months, $p=0.017$ ), DFS (17.6 vs. 31.5 months, $p=0.0134$ )
Table II. Correlation of GL1 with the traditional clinicopathologic parameters of $G C$.

\begin{tabular}{lc}
\hline Gender & $p=0.5904$ \\
Age & $p=0.5132$ \\
T3-T4 vs. T1-T2 & $\boldsymbol{p}=\mathbf{0 . 0 2 7 4}$ \\
N+ vs. N0 & $\boldsymbol{p}=\mathbf{0 . 0 3 2 4}$ \\
G3-G4 vs. G1-G2 & $p=0.3594$ \\
LVI1 $s$. LVI0 & $\boldsymbol{p}=\mathbf{0 . 0 2 8 7}$ \\
PnI1 vs. PnI0 & $\boldsymbol{p}<\mathbf{0 . 0 0 0 1}$ \\
M1 vs. M0 & $\boldsymbol{p}=\mathbf{0 . 0 4 4 6}$ \\
Stage 3-4 vs. 1-2 & $p=0.1926$ \\
& (trend: $p=0.0361)$ \\
Lauren's classification (diffuse $v s$. intestinal) & $\boldsymbol{p}=\mathbf{0 . 0 4 1 3}$ \\
Signet ring cells & $\boldsymbol{p}<\mathbf{0 . 0 0 0 1}$ \\
R1 vs. R0 & $p=0.2749$ \\
Palliative treatment & $\boldsymbol{p}=\mathbf{0 . 0 1 8 4}$ \\
Neoadjuvant treatment & $p=0.8273$ \\
Adjuvant treatment & $p=0.6547$ \\
LNR & $p=01178$ \\
& $($ trend: $p=0.0392)$ \\
Tumor site (proximal $v s$. distal) & $p=0.1544$ \\
WHO classification & $p=0.4610$ \\
Mortality & $p=0.1489$ \\
\hline
\end{tabular}

Categories and $p$-values written in bold are statistically significant $(\leq 0.05)$.

Table III. Univariate analysis of GL as prognostic factors for OS, PFS, DFS and TTP.

\begin{tabular}{lcc}
\hline Endpoints & $\begin{array}{c}\text { Median survival } \\
(\text { GL1 } v s . \text { GL0) }\end{array}$ & ANOVA \\
\hline OS & $18 \mathrm{mo} v s .32 \mathrm{mo}$ & $\boldsymbol{p = 0 . 0 2 1}$ \\
PFS & $18 \mathrm{mo} v s .32 \mathrm{mo}$ & $\boldsymbol{p = 0 . 0 2 1}$ \\
DFS & $17.6 \mathrm{mo} v s .31 .5 \mathrm{mo}$ & $\boldsymbol{p = 0 . 0 2 0}$ \\
TTP & $19 \mathrm{mo} v s .35 \mathrm{mo}$ & $\boldsymbol{p = 0 . 0 2 4}$ \\
\hline
\end{tabular}

mo: Months. Endpoints and $p$-values written in bold are statistically significant $(\leq 0.05)$.

and earlier TTP (19 vs. 35 months, $p=0.056$ ) (Figure $2 \mathrm{a}$ and d). Last, we wanted to assess the prognostic value of GL1 by univariate and multivariate analysis. The univariate model, in fact, revealed a strong correlation between GL and OS-PFS $(p=0.021)$, DFS $(p=0.020)$ and TTP $(p=0.024)$ (Table III); furthermore, the multivariate analysis identified GL1 as an independent prognostic factor for poor OS $(p=0.0287)$ (Table IV). All the reported data about GL1 (correlation with the other clinicopathologic parameters of aggressive tumor phenotype as well as its uni- and multivariate prognostic value in terms of worse survival), tend to confirm that intragastric exfoliation of GC is a metastatic route rather than a casual and meaningless event in the 

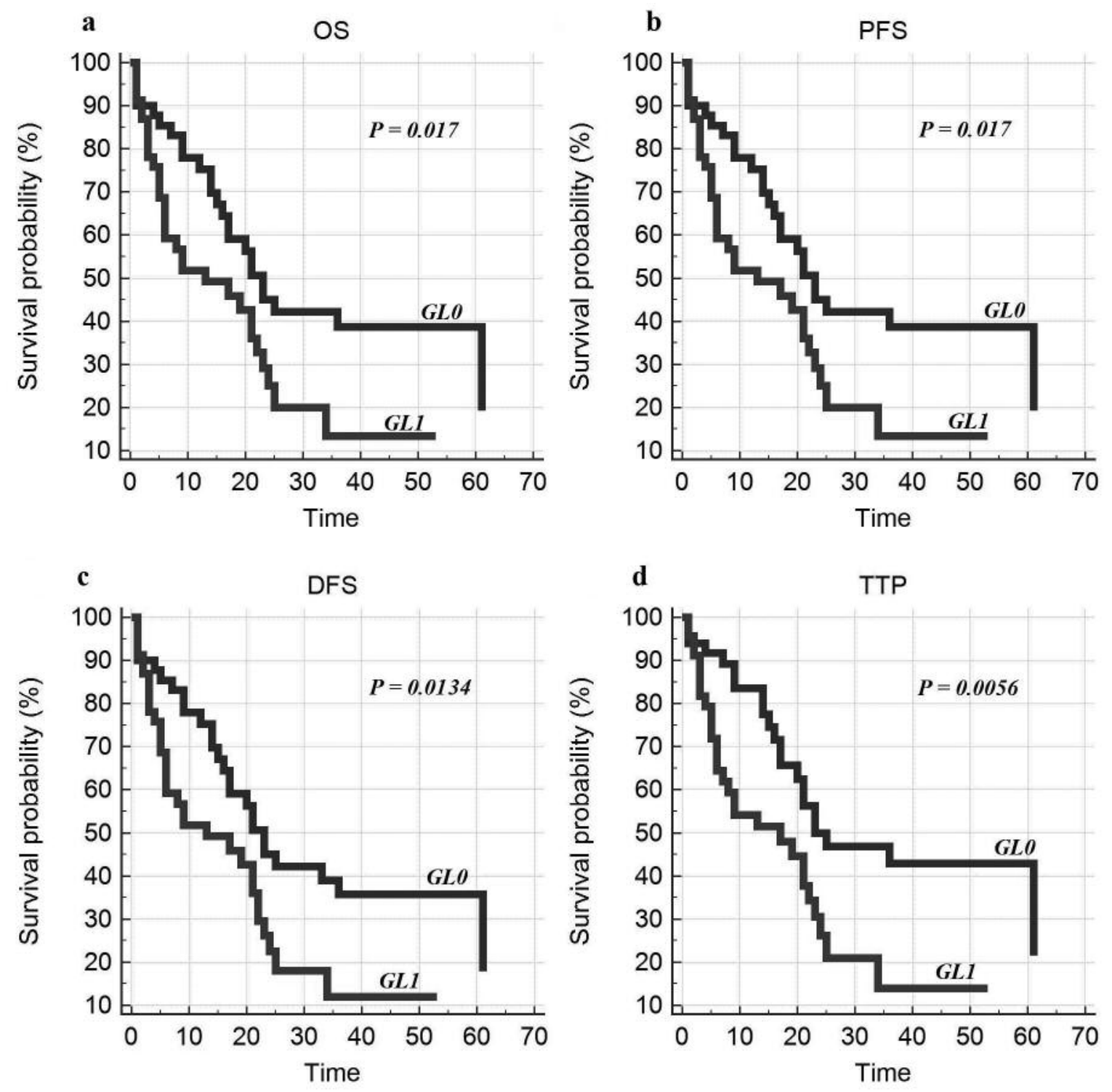

Figure 2. Kaplan-Meier curves of OS (2a), PFS (2b), DFS (2c) and TTP (2d) of GL1 and GLO groups.

natural history of this tumor (Figure 2) (15, 19-21). According to our previously published hypothesis, in fact, the GC cells, after breaking away from the paternal gastric tumor, could follow one of the five traditional metastatic pathways (direct invasion of contiguous structures, hematogenous route, lymphatic metastasis, transcelomatic spread and mesogastrium dissemination) or dive into the gastric lumen probably under the directions of specific signals coming from the neoplastic microenvironment (Figure 3) (15, 19-22). Differently from the classical patterns, however, the cells exfoliated in gastric juice (or GL) will be not allowed to set up any (enteric) metastasis due to the natural peristaltic propulsion and will meet with physiological degradation or natural expulsion with the feces $(15,19)$. The endoluminal route, videlicet, should be considered the mirror of the other five traditional spread patterns: should malignant cells be present in the gastric lumen (that is GL1), it is likely that other cancer cells have concomitantly migrated to blood, lymph nodes and so on $(15,19,20)$. Reliability, repeatability and reproducibility of our results as well as the small subset of the examined subjects represent indeed potential points of weakness of this study: future studies enrolling larger numbers of GC patients with a multi-institutional approach are needed as 
Table IV. Multivariate analysis of prognostic factors for OS.

\begin{tabular}{|c|c|c|c|c|c|c|}
\hline Independent variables & $\mathrm{b}$ & SE & Wald & $p$ & $\operatorname{Exp}(b)$ & $95 \% \mathrm{CI}$ of $\operatorname{EXp}(\mathrm{b})$ \\
\hline GL & 8.6106 & 3.9353 & 4.7875 & 0.0287 & 5489.7582 & 2.4533 to 12284611.9497 \\
\hline $\mathrm{T}$ & -5.0538 & 2.6179 & 3.7268 & 0.0535 & 0.0064 & 0.0000 to 1.0803 \\
\hline $\mathrm{N}$ & -8.1638 & 4.3358 & 3.5452 & 0.0597 & 0.0003 & 0.0000 to 1.3971 \\
\hline M & -17.5760 & 7.3000 & 5.7968 & 0.0161 & 0.0000 & $1.4221 \mathrm{E}-014$ to 0.0381 \\
\hline G & -8.9809 & 3.9390 & 5.1983 & 0.0226 & 0.0001 & 0.0000 to 0.2835 \\
\hline Lauren & 2.7232 & 1.7497 & 2.4224 & 0.1196 & 15.2297 & 0.4935 to 469.9517 \\
\hline WHO & -2.3550 & 1.0629 & 4.9089 & 0.0627 & 0.0949 & 0.0118 to 0.9621 \\
\hline Signet ring & 0.8019 & 1.8078 & 0.1967 & 0.6574 & 2.2297 & 0.0645 to 77.1041 \\
\hline LNR & 2.7418 & 2.1551 & 1.6186 & 0.2033 & 15.5152 & 0.2271 to 1059.8067 \\
\hline LVI & 7.8292 & 3.9437 & 3.9412 & 0.0471 & 2512.8751 & 1.1047 to 5716121.5094 \\
\hline PnI & -11.8381 & 5.2026 & 5.1776 & 0.0299 & 0.0000 & $2.6931 \mathrm{E}-010$ to 0.1938 \\
\hline $\mathrm{R}$ & -0.9415 & 2.7499 & 0.1172 & 0.7321 & 0.3901 & 0.0018 to 85.4826 \\
\hline Stage & 17.5266 & 7.9626 & 4.8449 & 0.0277 & 40896439.1985 & 6.8204 to $245 \mathrm{E}+012$ \\
\hline Gender & -2.6537 & 2.0137 & 1.7366 & 0.1876 & 0.0704 & 0.0014 to 3.6443 \\
\hline Age & 0.03686 & 0.03278 & 1.2644 & 0.2608 & 1.0376 & 0.9730 to 1.1064 \\
\hline Neoadjuvant treatment & -3.1069 & 2.8222 & 1.2119 & 0.2709 & 0.0447 & 0.0002 to 11.2979 \\
\hline Adjuvant treatment & -6.0504 & 2.1467 & 7.9436 & 0.0048 & 0.0024 & 0.0000 to 0.1584 \\
\hline
\end{tabular}

Overall model fit: $\mathrm{p}=0.0173$. b: The regression coefficient beta; SE: standard error; Wald: $\mathrm{b} / \mathrm{SE}^{2}$; $\mathrm{Exp}(\mathrm{b})$ : equals e to the power of each. beta value; CI: confidence interval. Variables and $\mathrm{p}$ values written in bold are statistically significant $(\leq 0.05)$.

validation. Respecting an appropriate timing of GL collection is fundamental to avoid false positives of GL1: in fact, gastroscopic biopsy, transmural fine needle aspirationbiopsy or intra-operative manipulation of the tumor can all cause neoplastic crevices setting malignant cells free in gastric juice or GL (23-25). Hence, we strongly advise collecting GL before such procedures commence.

\section{Conclusion}

In the light of our results, we can conclude that the expounded application of NGT could represent a valid resource available for the oncologic research on GC. The entire procedure - from NGT placement to cytopathologic analysis - is economic, simple, feasible, and safe: NGT insertion and GL were performed, in fact, only to patients under general anesthesia, orotracheally intubated and monitored, thereby minimizing risks of inadvertent complications (26). The value of GL1 as a parameter of aggressive tumor phenotype as well as its prognostic value could ameliorate the current methods of classification, staging and prognosis of GC patients and help identify subjects deserving a closer follow-up or adjuvant treatment even at early phases of disease (16). Should our data be confirmed by future works, NGT could be assessed as an indispensable oncologic measure for GC.

\section{Conflicts of Interest}

The Authors declare no conflicts of interest.

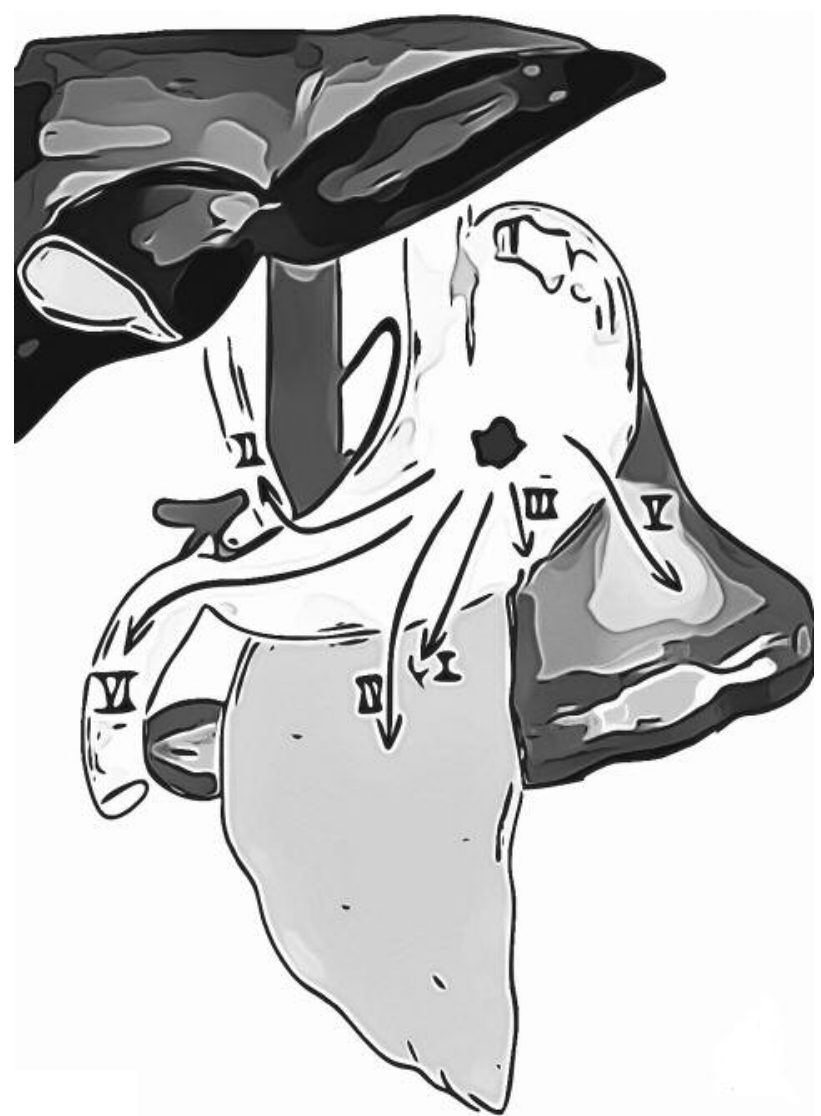

Figure 3. Scheme of the six metastatic routes followed by GC. I: Direct infiltration of contiguous structures; II: hematogenous invasion; III: lymphatic metastasis; IV: transcoelomic dissemination; V: mesogastrium spread; VI: endoluminal exfoliation. 


\section{References}

1 Itkin M, DeLegge MH, Fang JC, McClave SA, Kundu S, Janne d'Othee B, Martinez-Salazar GM, Sacks D, Swan TL, Towbin RB, Walker TG, Wojak JC, Zuckerman DA and Cardella JF: Multidisciplinary practical guidelines for gastrointestinal access for enteral nutrition and decompression from the Society of Interventional Radiology and american Gastroenterological Association (AGA) Institute, with endorsement by Canadian Interventional Radiological Association (CIRA) and Cardiovascular and Interventional Radiological Society of Europe (CIRSE). J Vasc Interv Radiol 22: 1089-1106, 2011.

2 Cresci G and Mellinger J: The history of nonsurgical enteral tube feeding access. Nutr Clin Pract 21: 522-528, 2006.

3 Donkor J, Armenian P, Hartman IN and Vohra R: Analysis of gastric lavage reported to a statewide poison control system. J Emerg Med 51: 394-400, 2016.

4 Huang ES, Karsan S, Kanwal F, Singh I, Makhani M and Spiegel BM: Impact of nasogastric lavage on outcomes in acute GI bleeding. Gastrointest Endosc 74: 971-980, 2011.

5 Bates M, O’Grady J, Maeurer M, Tembo J, Chilukutu L, Chabala C, Kasonde R, Mulota P, Mzyece J, Chomba M, Mukonda L, Mumba M, Kapata N, Rachow A, Clowes P, Hoelscher M, Mwaba P and Zumla A: Assessment of the Xpert MTB/RIF assay for diagnosis of tubercolosis with gastric lavage aspirates in children in sub-Saharan Africa: a prospective descriptive study. Lancet Infect Dis 13: 36-42, 2013.

6 Sharma P, Nangia S, Tiwari S, Goel A, Singla B and Saili A: Gastric lavage for prevention of feeding problems in neonates with meconium-stained amniotic fluid: a randomized controlled trial. Paediatr Int Child Health 34: 115-119, 2014.

7 Carrère N, Seulin P, Julio CH, Bloom E, Gouzi JL and Pradère $\mathrm{B}$ : Is nasogastric or nasojejunal decompression necessary after gastrectomy? A prospective randomized trial. World J Surg 31: 122-127, 2007.

8 Lin CH, Liu NJ, Lee CS, Tang JH, Wie KL, Yang C, Sung KF, Cheng CL, Chiu CT and Chen PC: Nasogastric feeding tube placement in patients with esophageal cancer: application of ultrathin transnasal endoscopy. Gastrointest Endosc 64: 104-107, 2006.

9 Nakanishi H, Kurosaki M, Takahashi Y, Itakura J, Ueda K, Suzuki S, Yasui Y, Tamaki N, Nakakuki N, Takada H, Ueda M, Hayashi T, Kuwabara K, Takaura K, Higuchi M, Komiyama Y, Yoshida $\mathrm{T}$ and Izumi $\mathrm{N}$ : Pretreatment gastric lavage reduces postoperative bleeding after endoscopic submucosal dissection for gastric neoplasms. PLoS One 11: e0149235, 2016.

10 Triantafillidis JK and Cheracakis P: Diagnostic evaluation of patients with early gastric cancer-a literature review. Hepatogastroenterology 51: 618-624, 2004.

11 Traut HF, Rosenthal M, Harrison JT, Farber SM and Grimes OF: Evaluation of cytologic diagnosis of gastric cancer. Surg Gynecol Obstet 95: 709-716, 1952.

12 Gupta S, Annamma ML and Gupta S: Simple gastric lavage cytology in carcinoma stomach; ist relevance to developing countries. Trop Geogr Med 30: 483-486, 1978.

13 Sivak MV: Gastrointestinal endoscopy: past and future. Gut 55: 1061-1064, 2006.

14 Morreno-Otero R, Martinez-Raposo A, Cantero J and Pajares JM: Exfoliative cytodiagnosis of gastric adenocarcinoma. Comparison with biopsy and endoscopy. Acta Cytol 27: 485-488, 1983.
15 Virgilio E, Giarnieri E, Montagnini M, D’Urso R, Proietti A, Mesiti A, Giovagnoli MR, Mercantini P, Cavallini M and Balducci G: Analyzing gastric lavage of gastric cancer patients: a prospective observational study on cytopathology and determination of intragastric CEA, Ca 19.9, Ca 72.4 and Ca 50. Acta Cytol 60: 161-166, 2016.

16 Virgilio E, Giarnieri E, Giovagnoli MR, Montagnini M, Proietti A, D'Urso R, Mercantini P, Balducci G and Cavallini M: Early gastric cancer exfoliating into gastric lavage (GL1 EGC) shows a more aggressive behavior and poorer survival compared tot he non-exfoliative counterpart (GL0 EGC). Anticancer Res 37: 4199-4203, 2017.

17 Virgilio E, Giarnieri E, Giovagnoli MR, Montagnini M, Proietti A, D’Urso R, Nigri G, Mercantini P, Ramacciato G, Cavallini M and Balducci G: Presence of cancer cells in gastric lavage of gastric cancer patients as an indicator of advanced disease, predictor of tumour aggressive phenotype and independent prognostic factor for poor survival: The endoluminal metastatic pathway of gastric cancer and GL0/GL1 classification. Cytopathology, 2017. doi: 10.1111/cyt.12484. [Epub ahead of print]

18 Edge SB and Compton CC: The American Joint Committee on Cancer: the 7th edition oft he AJCC cancer staging manual and the future of TNM. Ann Surg Oncol 17: 1471-1474, 2010.

19 Virgilio E, Giarnieri E, Montagnini M, D’Urso R, Proietti A, Mesiti A, Giovagnoli MR, Mercantini P, Cavallini M and Balducci G: Detection of cancer cells and tumor markers in gastric lavage of patients with gastric cancer: do these findings have a clinicopathological significance and oncological implication? Med Hypotheses 94: 1-3, 2016.

20 Virgilio E, D'Antonio C and Balducci G: Mesogastrium recurrence as expression ofthe fifth metastatic route of gastric cancer. Med Hypotheses 82: 403-404, 2014.

21 Virgilio E, Proietti A, D’Urso R, Cardelli P, Giarnieri E, Montagnini M, Giovagnoli MR, Mercantini P, Balducci G and Cavallini M: Measuring intragastric tumor markers in gastric cancer patients: a systematic literature review on significance and reliability. Anticancer Res 37: 2817-2821, 2017.

22 Christofori $G$ and Semb $H$ : The role ofthe cell-adhesion molecule E-cadherin as a tumour-suppressor gene. Trends Biochem Sci 24: 73-76, 1999.

23 Yu XF, Ma YY, Hu XQ, Zhang QF and Ye ZY: Analysis of exfoliated gastric carcinoma cells attached on surgical supplies. Onco Targets Ther 7: 1869-1873, 2014.

24 Levy MJ, Gleeson FC, Campion MB, Caudill JL, Clain JE, Halling K, Rajan E, Topazian MD, Wang KK, Wiersema MJ and Clayton A: Prospective cytological assessment of gastrointestinal luminal fluid acquired during EUS: a potential source of falsepositive FNA and needle tract seeding. Am J Gastroenterol 105: 1311-1318, 2010.

25 Virgilio E, Mercantini P, Ferri M, Cunsolo G, Tarantino G, Cavallini $\mathrm{M}$ and Ziparo V: Is EUS-FNA of solid-pseudopapillary neoplasms oft he pancreas as a preoperative procedure really necessary and free of acceptable risks? Pancreatology 14: 536-538, 2014.

26 Kannappan O:Havoc caused by nasogastric tube: lesson to be learned. ANZ J Surg 85: 388-389, 2015.

Received November 7, 2017

Revised November 15, 2017

Accepted November 17, 2017 